\title{
Nutrient capture from aqueous waste and photo-controlled fertilizer delivery to tomato plants using Fe(III)-polysaccharide hydrogels
}

M. H. Jayan S. Karunarathna ${ }^{\mathrm{a}, \mathrm{b}}$, Kerri M. Bailey ${ }^{\mathrm{a}, \mathrm{b}}$, Bethany L. Ash ${ }^{\mathrm{a}}$, Paul G. Matson ${ }^{\mathrm{c}, \mathrm{d}}$, Hans Wildschutte $^{\mathrm{c}}$, Timothy W. Davis ${ }^{\mathrm{c}}$, W. Robert Midden ${ }^{\mathrm{a}}$ Alexis D. Ostrowski ${ }^{\mathrm{a}, \mathrm{b}}$ *

${ }^{a}$ Department of Chemistry, Bowling Green State University, Bowling Green, Ohio 43403, USA

${ }^{\mathrm{b}}$ Center for Photochemical Sciences, Bowling Green State University, Bowling Green, Ohio 43403, USA

${ }^{\mathrm{c}}$ Department of Biological Sciences, Bowling Green State University, Bowling Green, Ohio 43403, USA

${ }^{\mathrm{d}}$ Environmental Sciences Division, Oak Ridge National Laboratory, Oak Ridge, TN 37831, USA

Corresponding author: Alexis D. Ostrowski

alexiso@bgsu.edu

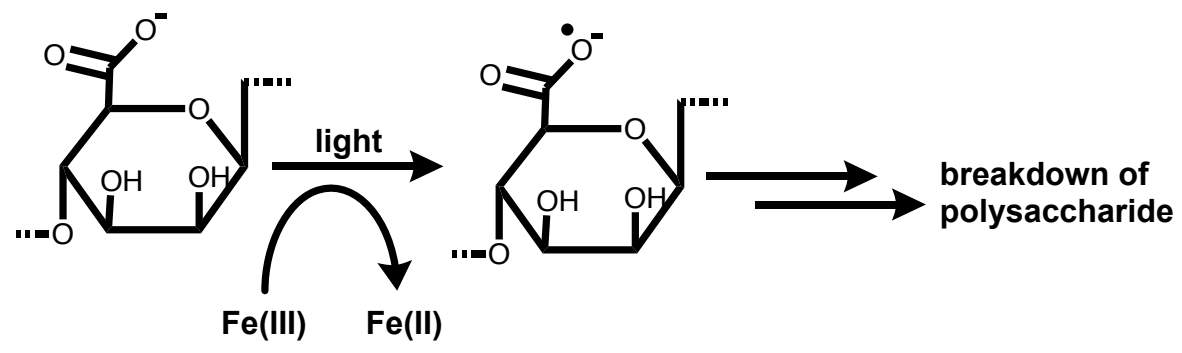

Figure S1. Photochemical reaction scheme responsible for degredation of the Fe(III)-polysaccharide hydrogels 


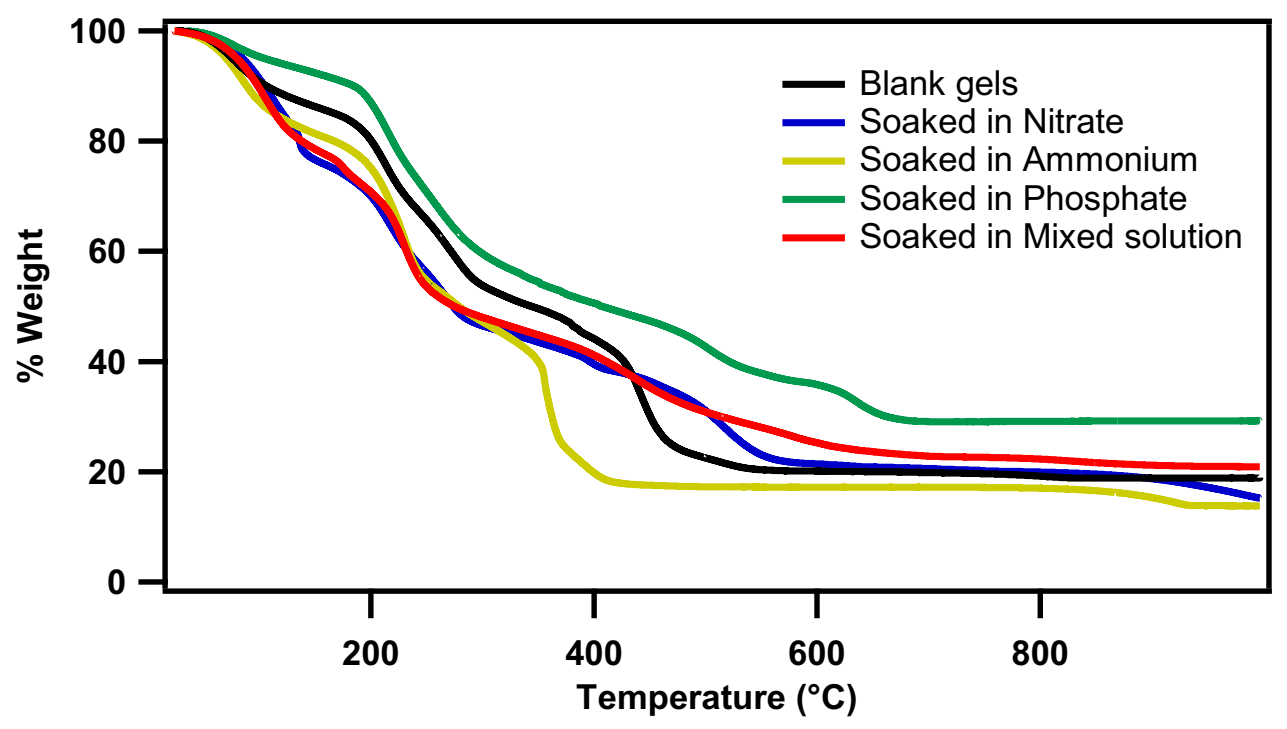

Figure S2. Thermogravimetric analysis (TGA) of Fe(III)-alginate beads before (blank gels) and after soaking in different nutrient solutions for 24 hours.

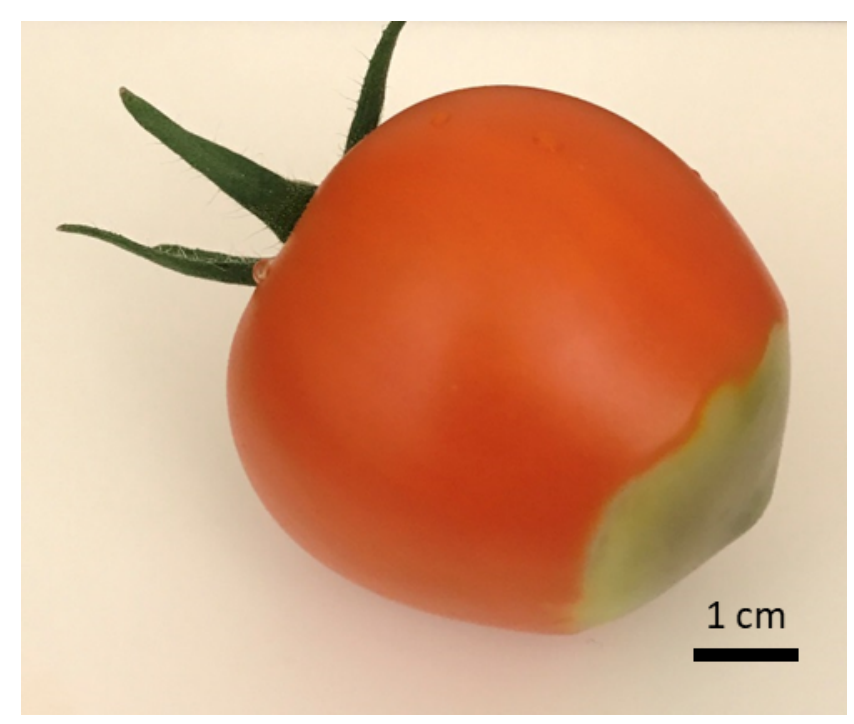

Figure S3. Blossom end rot in a tomato from fertilizer solution treatment. 


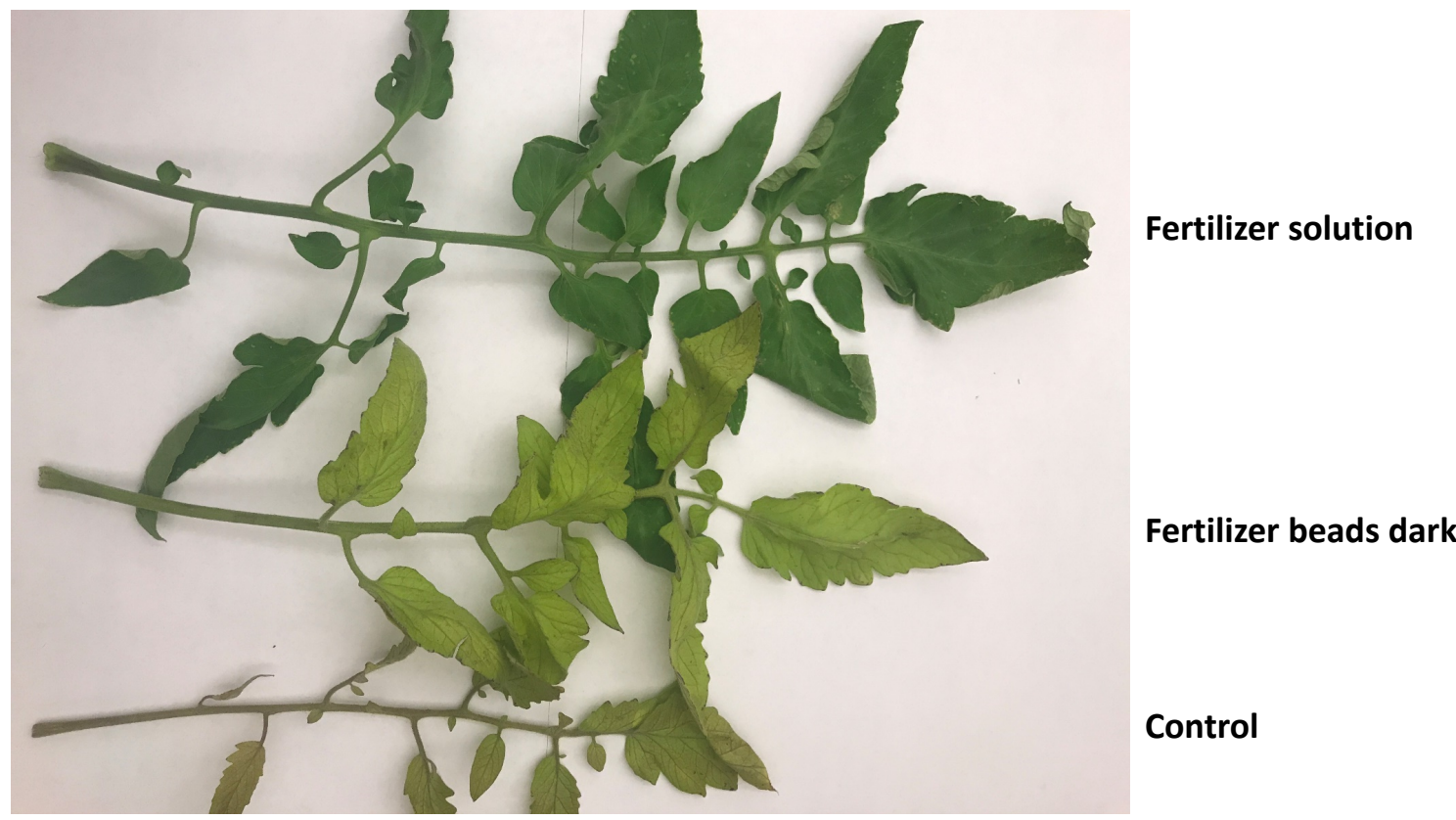

Figure S4. Tomato leaves from different treatments with significant changes in their green color visible to naked eye.

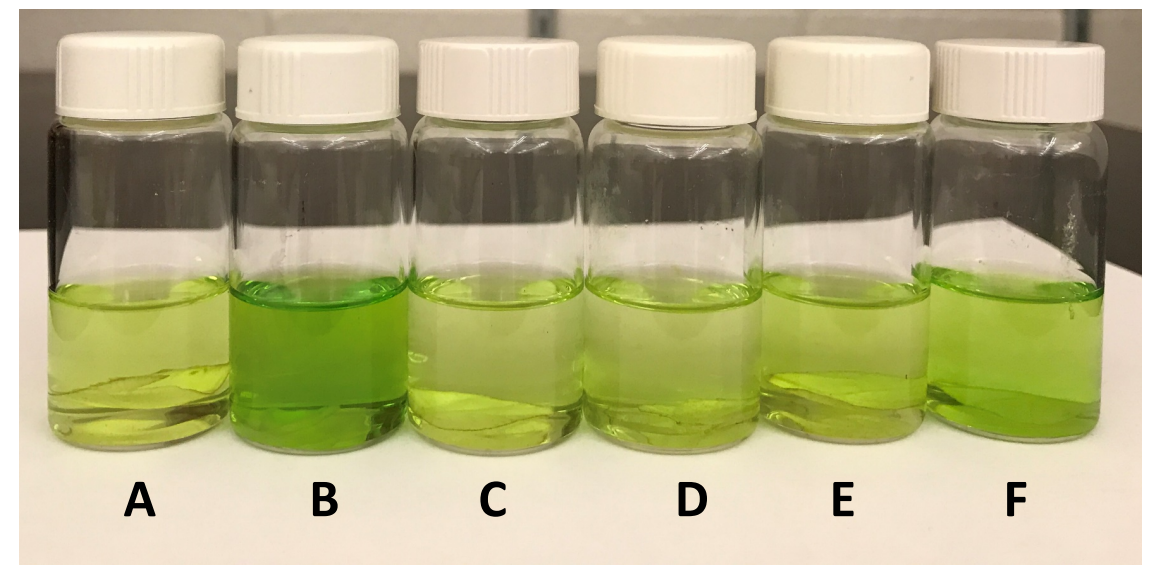

A - Control

$B$ - Fertilizer solution

C - Control beads dark

D - Control beads light

E - Fertilizer beads dark

F - Fertilizer beads light

Figure S5. Chlorophyll extracted from tomato leaves of each condition showing differences visible to naked eye. 


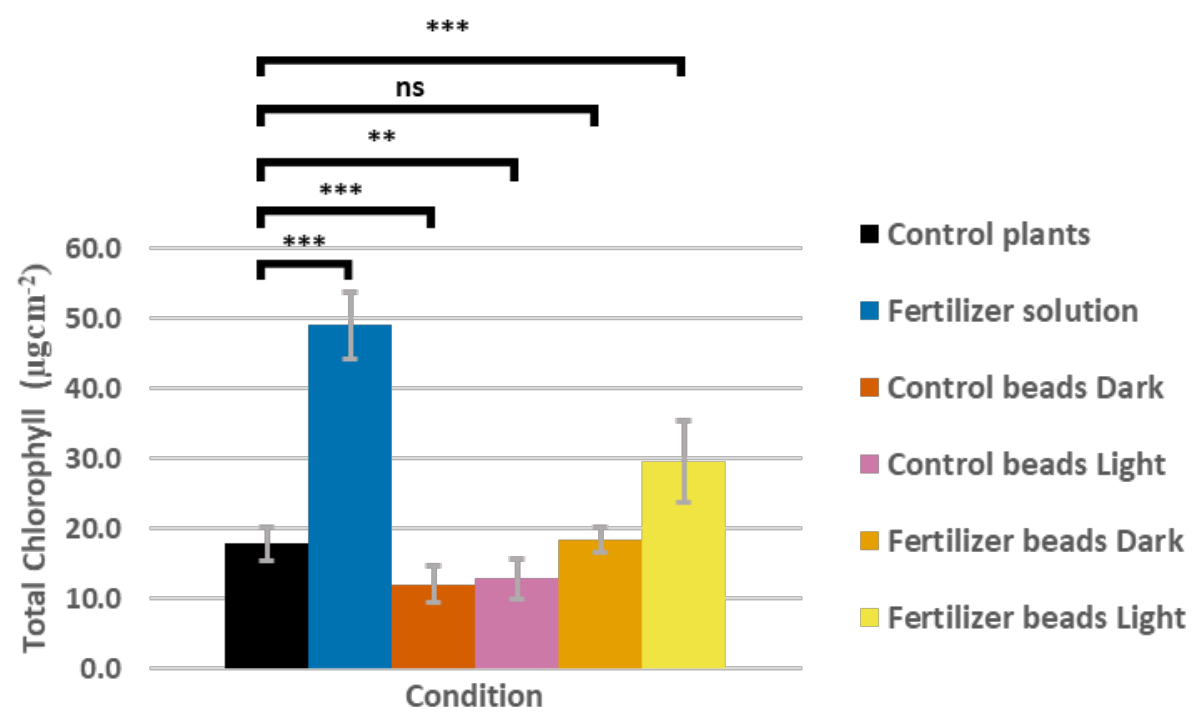

Figure S6. Total chlorophyll content of tomato leaf samples from different conditions. ns, **, *** represent $\mathrm{p}>0.05, \mathrm{p}<0.01$ and $\mathrm{p}<$ 0.001 respectively.

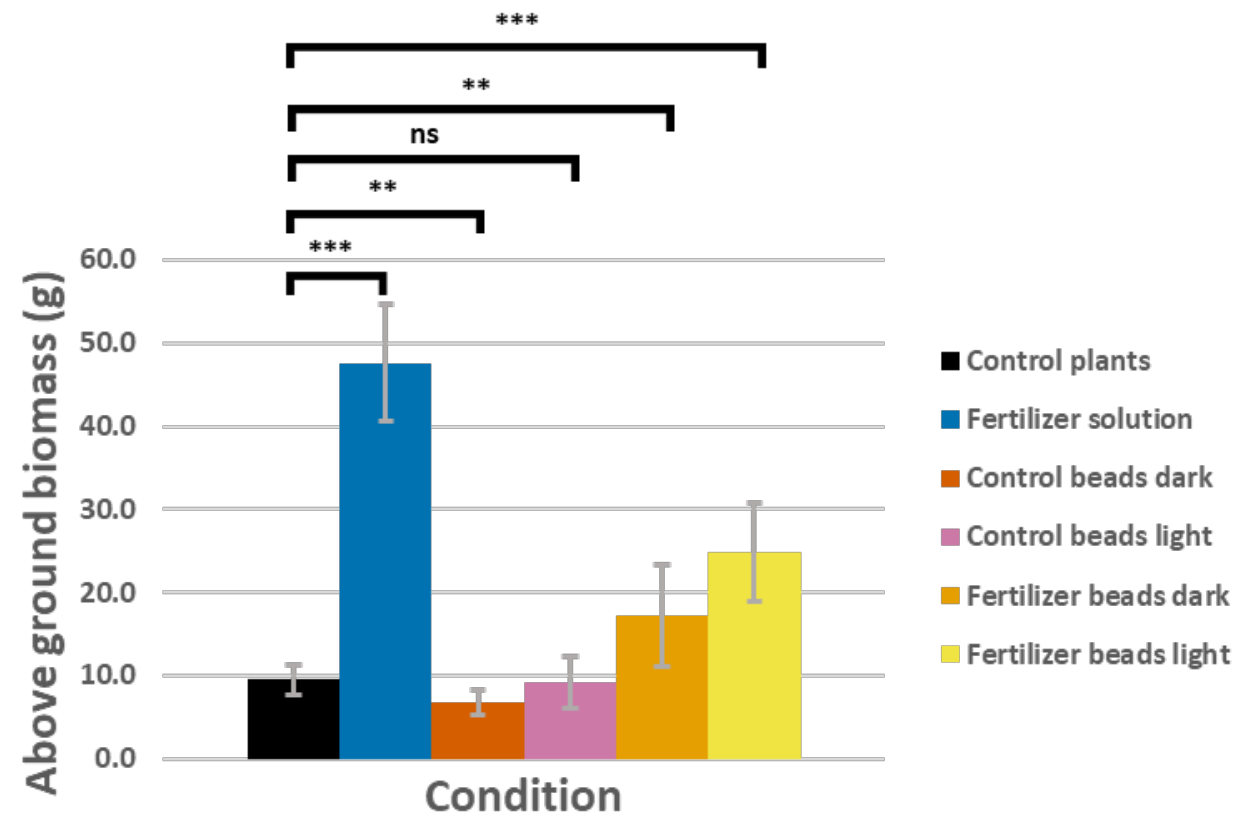

Figure S7. Above ground biomass for tomato plants grown with six different conditions in the greenhouse. ns, **, *** represent $\mathrm{p}>0.05$, $\mathrm{p}<0.01$ and $\mathrm{p}<0.001$ respectively. 


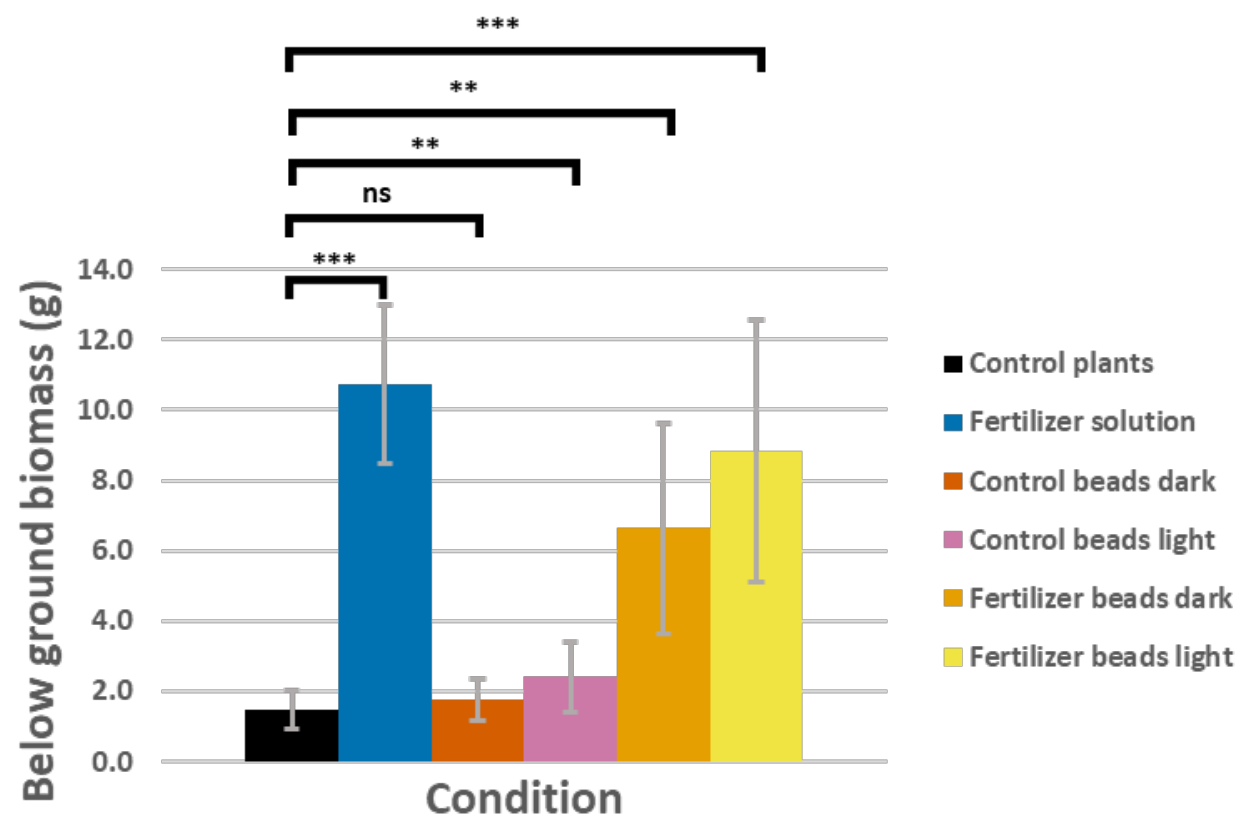

Figure S8. Below ground biomass for tomato plants grown with six different conditions in the greenhouse. ns, **, *** represent $\mathrm{p}>0.05$, $\mathrm{p}<0.01$ and $\mathrm{p}<0.001$ respectively.

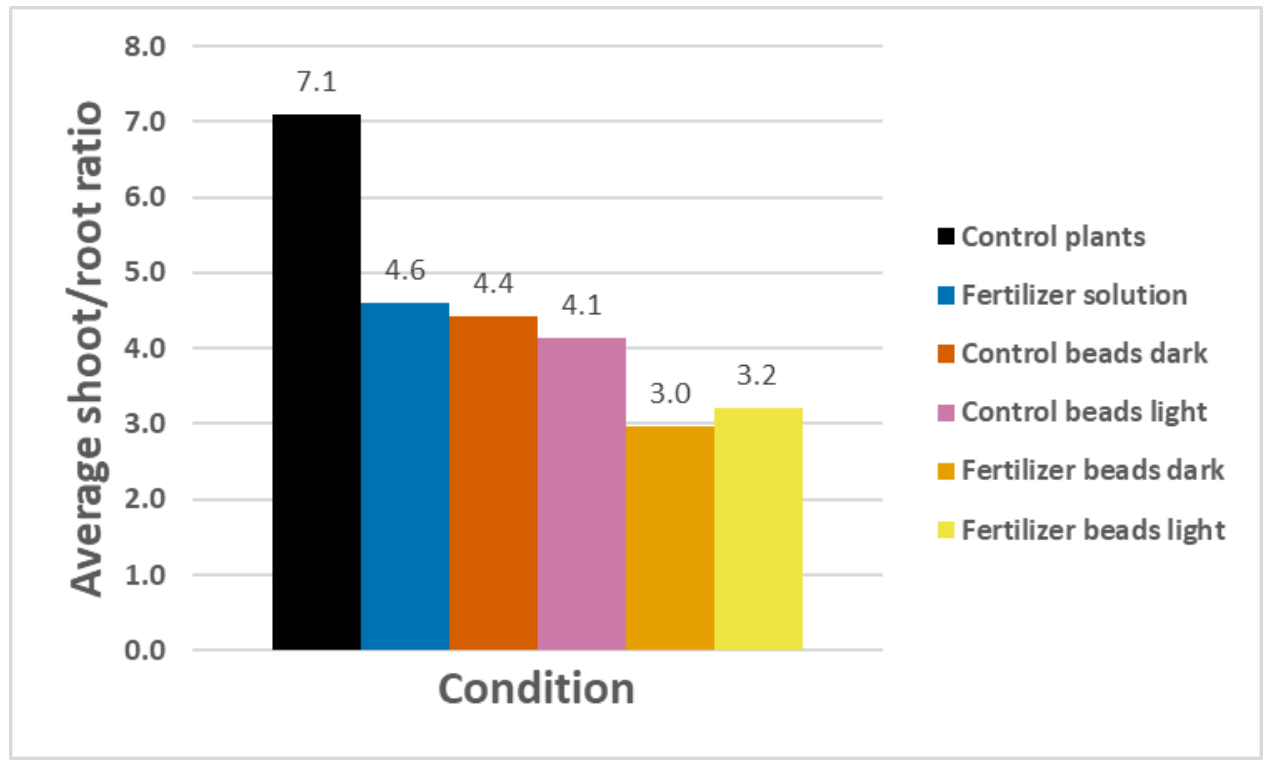

Figure S9. Shoot to root ratio (SR ratio) for tomato plants grown with six different conditions in the greenhouse. 


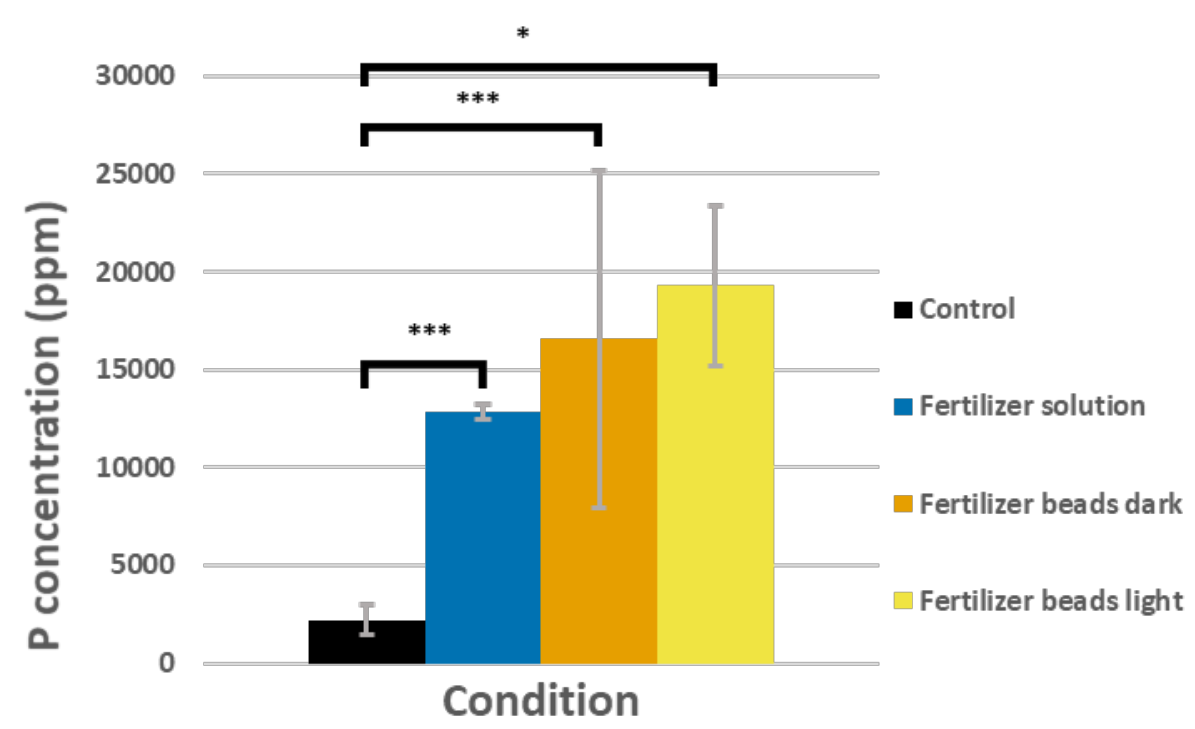

Figure S10. ICP-MS analysis for phosphorus in tomato leaf samples from selected conditions. * and ${ }^{* * *}$ represent $\mathrm{p}<0.05$ and $\mathrm{p}<0.001$ respectively.

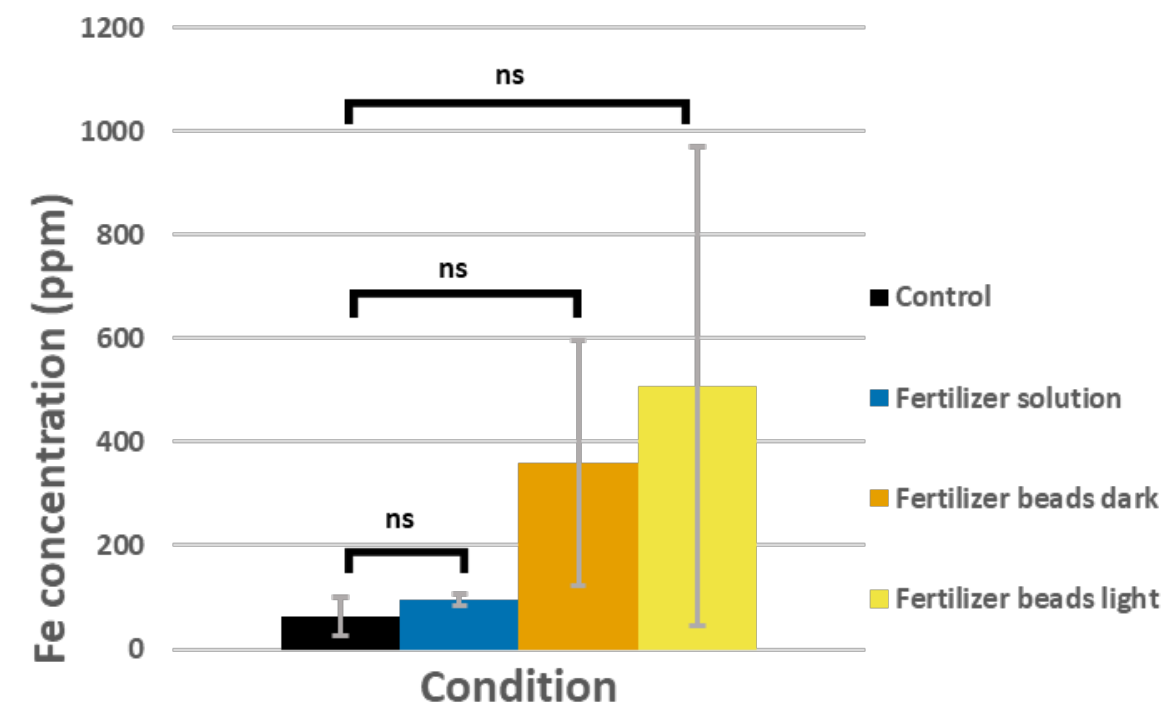

Figure S11. ICP-MS analysis for iron in tomato leaf samples from selected conditions. ns represents $\mathrm{p}>0.05$. 

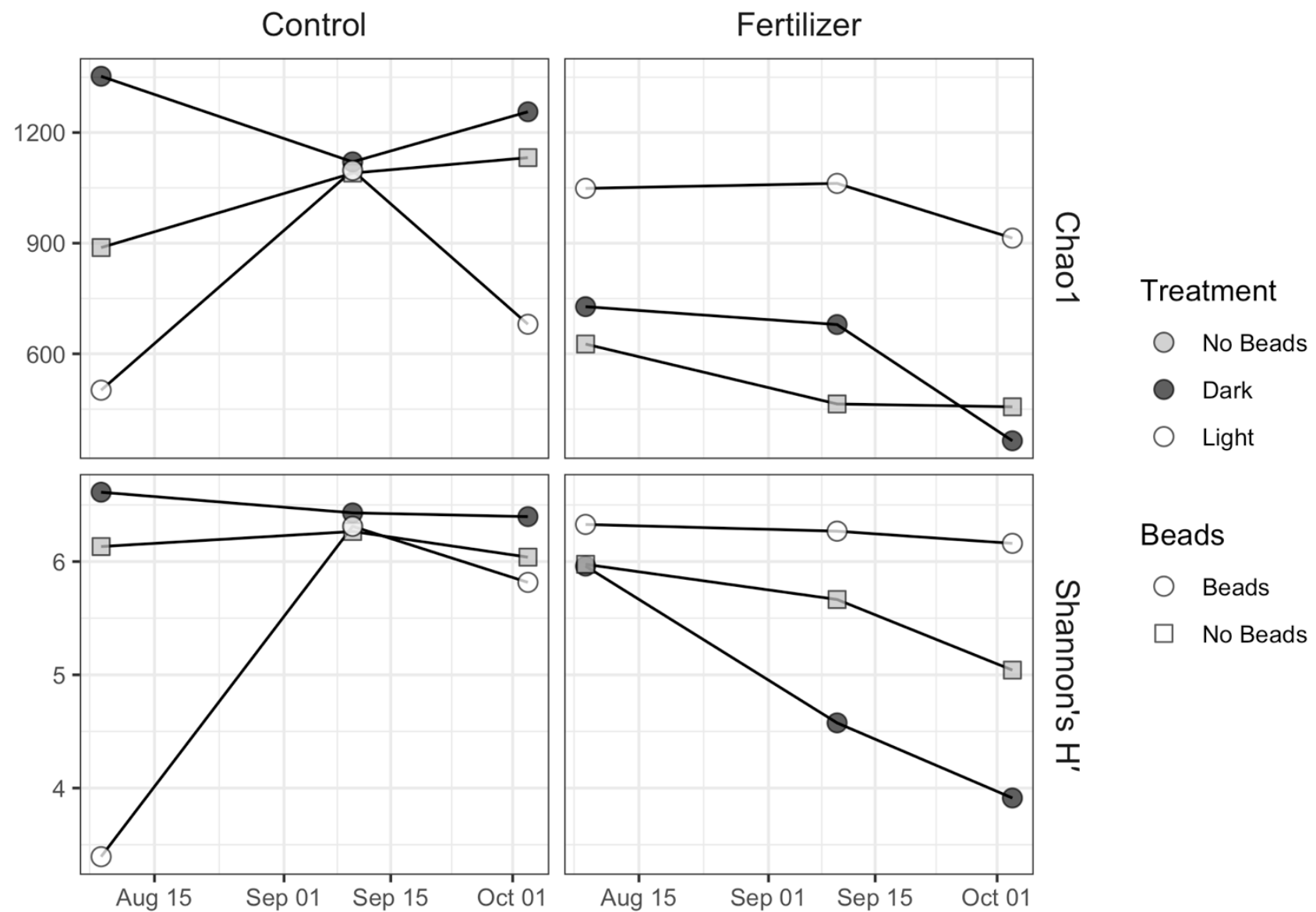

\section{Beads}

$\bigcirc$ Beads

$\square \quad$ No Beads

Figure S12. Temporal changes in ASV richness (Chao1) and diversity (Shannon's H' index) of soil bacterial assemblages from Control (left column) and Fertilized pots (right column). 


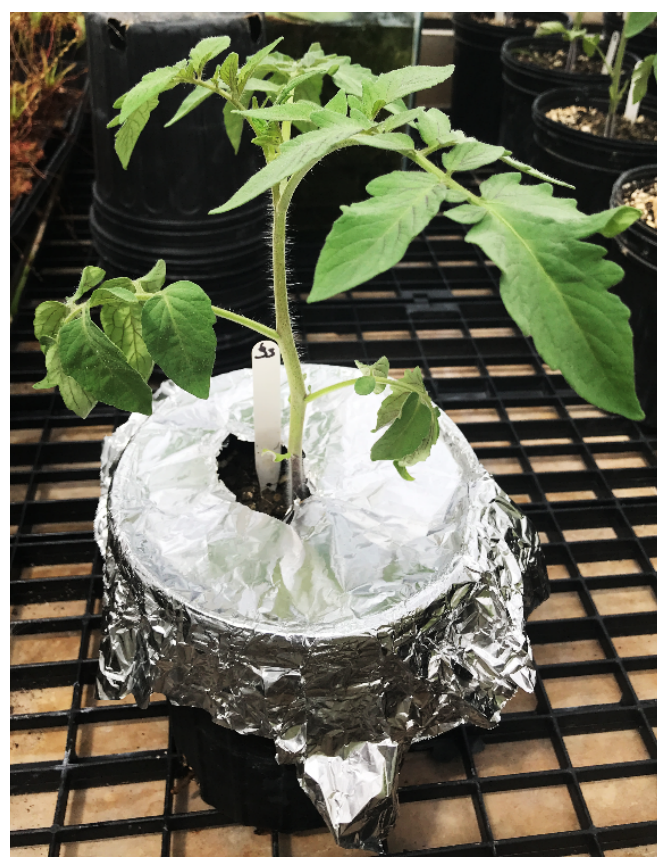

Figure S13. Tomato plants with dark conditions for gel beads with aluminum foil.

Table S1. Selected average tomato plant heights $(\mathrm{cm})$ from the six different conditions.

\begin{tabular}{|l|l|l|l|}
\hline \multirow{2}{*}{} & \multicolumn{3}{|c|}{ Average plant height \pm S.D. / cm } \\
\cline { 2 - 4 } & \multicolumn{1}{|c|}{53 days } & \multicolumn{1}{|c|}{81 days } & \multicolumn{1}{c|}{109 days } \\
\hline Control & $35 \pm 8.7$ & $77.9 \pm 5$ & $103.1 \pm 16.0$ \\
\hline Fertilizer solution & $56.5 \pm 2.0$ & $85 \pm 3.5$ & $110.3 \pm 9.2$ \\
\hline Control beads dark & $47.3 \pm 3.5$ & $77.6 \pm 11.8$ & $84.3 \pm 18.6$ \\
\hline Control beads light & $45.5 \pm 2.3$ & $77.3 \pm 10.3$ & $93.6 \pm 28.7$ \\
\hline Fertilizer beads dark & $49.1 \pm 2.2$ & $81.9 \pm 16.8$ & $102.6 \pm 34.7$ \\
\hline Fertilizer beads light & $37.6 \pm 8.1$ & $94.8 \pm 6.9$ & $139.9 \pm 21.4$ \\
\hline
\end{tabular}

